INTERNATIONAL DESIGN CONFERENCE - DESIGN 2018

https://doi.org/10.21278/idc.2018.0531

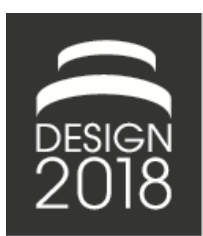

\title{
CLASSIFICATION OF BIO-DESIGN APPLICATIONS: TOWARDS A DESIGN METHODOLOGY
}

\author{
R. Esat and S. Ahmed-Kristensen
}

\begin{abstract}
Bio-design is a novel frontier in design research. So far no methodology has been concieved for biodesign. A methodology would render the field more accessible by those without deep biology knowledge. Existing bio-design applications were reviewed and a novel classification scheme was proposed. The classification scheme forms the initial step towards the design methodology and is also a key contribution to the emerging field of bio-design.
\end{abstract}

Keywords: design methodology, biomimicry (biomimetics), bio-design classification, biologically inspired design

\section{Introduction}

The ISO/TC 266 Biomimetics committee has recently published the following definition of bio-inspired design as "a creative approach based on the observation of biological systems". Furthermore, they define biomimetic design as "the interdisciplinary cooperation of biology and technology or other fields of innovation with the goal of solving practical problems through the function analysis of biological systems, their abstraction into models, and the transfer into and application of these models to the solution" (ISO/TC 266, 2015). A new design paradigm, bio-design incorporates living organism and their processes as well as material derived from living organisms. This presents a new frontier in terms of design with nature as opposed to design by nature in the case of bio-inspired design. Bio-design was coined by William Myers in 2012 as "an emerging and often radical approach to design that draws on biological tenets and even incorporates the use of living materials into structures, objects and tools" (Myers, 2012) In this paper, bio-design is defined as a novel frontier in design research which incorporates the lifelike properties of living or once living organisms and their processes and their reappropriation to human-facing contexts and industries. Bio-design is an emerging field with multiple potential application sectors as illustrated by the current breadth in research fields that are incorporating bio-design principles. Application sectors in which bio-design is used currently include energy, light production and material research. Some applications include bacteria to produce bricks (bioMASON, 2016), microbial fuel cells (Rahimnejad et al., 2015) and glowing plants as a domestic light source (Glowing Plant, 2013). Bio-design presents a novel addition to the "sustainable design tool -box" and poses an alternative means by which to solve design problems in the most sustainable way possible. Furthermore, the remit of bio-design may be potentially further-reaching than traditional bio-inspired design or bio-mimetic design.

The long-term aim of this research is to create a design methodology around bio-design as well as to evaluate the methodology via the development of example applications. This paper presents the initial research of this process. The aim of this paper is to present a classification system of existing bio-design 
applications. By ascertaining the breadth of possible applications, the classification system discussed in this paper presents a stepping stone towards the design methodology for bio- design.

Bio-design is viewed as an extension of bio-inspired design that goes beyond the remit of bio-inspired design by the incorporation of living or once-living organic components. Bio-inspired methodologies were therefore reviewed in order to assess the need for a bio-design methodology. The literature review identified that design methodologies have been devised for bio-inspired design, and that they are successful to increase novelty in innovation (Ahmed-Kristensen et al., 2014; Keshwani et al., 2017). Bio-inspired design methodologies resulted from a thorough review of bio-inspired applications. The research being conducted to develop a design methodology in bio-design is at the review of applications stage. This section will present the research in bio-inspired design that has provided the evidence for the need of a design methodology for bio-design.

\subsection{Bio-inspired design applications}

The literature review identified that bio-inspired applications are very hard to locate in literature. Those that are found in literature do not reference any design process such as a paper written on structural colour materials (Shang et al., 2016). Companies and university-level research developing bio-inspired solutions cite an $a d h o c$ and unsystematic process of design, if any, in which a function is noticed in nature that was the source of their inspiration (Wen et al., 2014; AskNature Team, 2016; Kyoo-Chul et al., 2013). For this reason design methodologies were created as a search engine of biological strategies to transform the process of bio-inspired design into a systematic and exhaustive process.

\subsection{Bio-inspired design methodology}

Three major classes of bio-inspired methodology were identified. The methodologies facilitate engineers to find relevant biological solutions to engineering problems. The biological solutions may form the basis for bio-mimetic design solutions or inspiration to address a particular engineering design problem in the case of bio-inspired design. The methodologies support the mapping between biological mechanisms and engineering design problems.

a) Taxonomy Software. These are web platforms or software designed to facilitate the identification of biological examples. The taxonomy software are: AskNature (2016) and Design by Analogy to Nature Engine (DANE) (Goel, 2011). In both cases, biological strategies are presented in a taxonomy of 'functional models'.

b) Bio-Processes. These present a list of steps, which if followed successfully aid the mapping of biological solution to engineering problem. Bio-processes have been detailed in papers such as Helms et al. (2008) in which top-down and bottom-up processes were compared as well as Mak and Shu (2008), which develops a list of steps around biological descriptions and ideation.

c) Bio-Algorithms. Fernandez-Marquez et al. (2013) present a catalogue of biological patterns as well as a means of mimicking each one for computational output. These are a 'cut \& paste friendly' set of rules that allow software engineers to program biologically inspired systems.

The literature review in bio-inspired design applications and methodology conveyed the need for a design methodology in bio-design because it has been shown that bio-inspired design methodologies increase novelty and innovation. Results reported by Keshwani et al. (2013) showed that biocards aided ideation at relatively higherlevels of abstraction than brainstorming achieved. Furthermore, AhmedKristensen et al. (2014) showed that distant analogies including biocards increased the novelty of solutions, with biocards being more useful than random distant analogies. Thus, although similar research has not be conducted for bio-design, it may be extrapolated that a design methodology around bio-design would allow for the conception of more innovative and creative solutions. Further, it would allow for the more frequent, efficient and successful incorporation of bio-design principles in a variety of industries and contexts. Furthermore, it would support the identification of living or once-living organisms and their processes in their re-appropriation to human-facing contexts and industries.

This paper puts forward two main contributions to current knowledge: a full and systematic review of current bio-design applications and the development of a classification system. The classification system forms the first step in the conception of a design methodology. The findings presented in this paper also contribute to further establish bio-design more firmly as a novel design paradigm. 
A design methodology in bio-design would allow practitioners to utilise this novel tool more successfully and efficiently in the future. It would allow for its systematic application, rather than the ad hoc process that is commonly observed. Further, there are many potential advantages of the integration of organisms, particularly microorganisms into human-facing manufacturing processes and outcomes. Microorganisms are able to react in real-time to never-seen-before stimuli, in a way that rivals computational artificial intelligence. They are able to integrate a multitude of sensory stimuli and coordinate an appropriate response (Armstrong, 2016). In addition, there is evidence to support biodesign from a sustainability perspective. BioMASON uses bacteria to dry bricks rather than the traditionally high oven temperatures, this proposes a theoretical decrease in 800 million tonnes of carbon emissions annually. Further, $40 \%$ of global carbon dioxide emissions are due to the construction industry and thus an alternative to this presents a sustainable solution to producing bricks (bioMASON, 2016). Glowee, a company that are developing alternative urban lighting using bioluminescent bacteria also proposes benefits in terms of sustainability. There is not energy wastage due to heat loss as the light is cold, and does not need any burning of coal to produce light. Furthermore, the light is less intense so is less damaging for eyes and produces a decreased amount of light pollution (Glowee, 2016). A design methodology would allow bio-design to be more accessible for practitioners of a range of fields, whom do not have specialist biological knowledge. In this way, tenets of bio-design may be used consistently, successfully and more easily in a range of fields.

\section{Research aims}

As previously discussed, the long-term aim of this research is the development and evaluation of a design methodology; evaluation will be achieved via the creation of example applications. This paper presents the initial steps to achieve the long-term goals. The aim of this research presented in this paper was to gain further knowledge about existing bio-design applications; applications must be characterised in order to gain a full overview of the field within engineering and design contexts. Furthermore, the aim of the research was to create a classification system. The classification system of current bio-design applications presents the first step towards the creation of the design methodology. As such, the parameters and constraints of the design methodology will be informed by data presented in this paper. The research also aimed to identify any existing methodologies around bio-design.

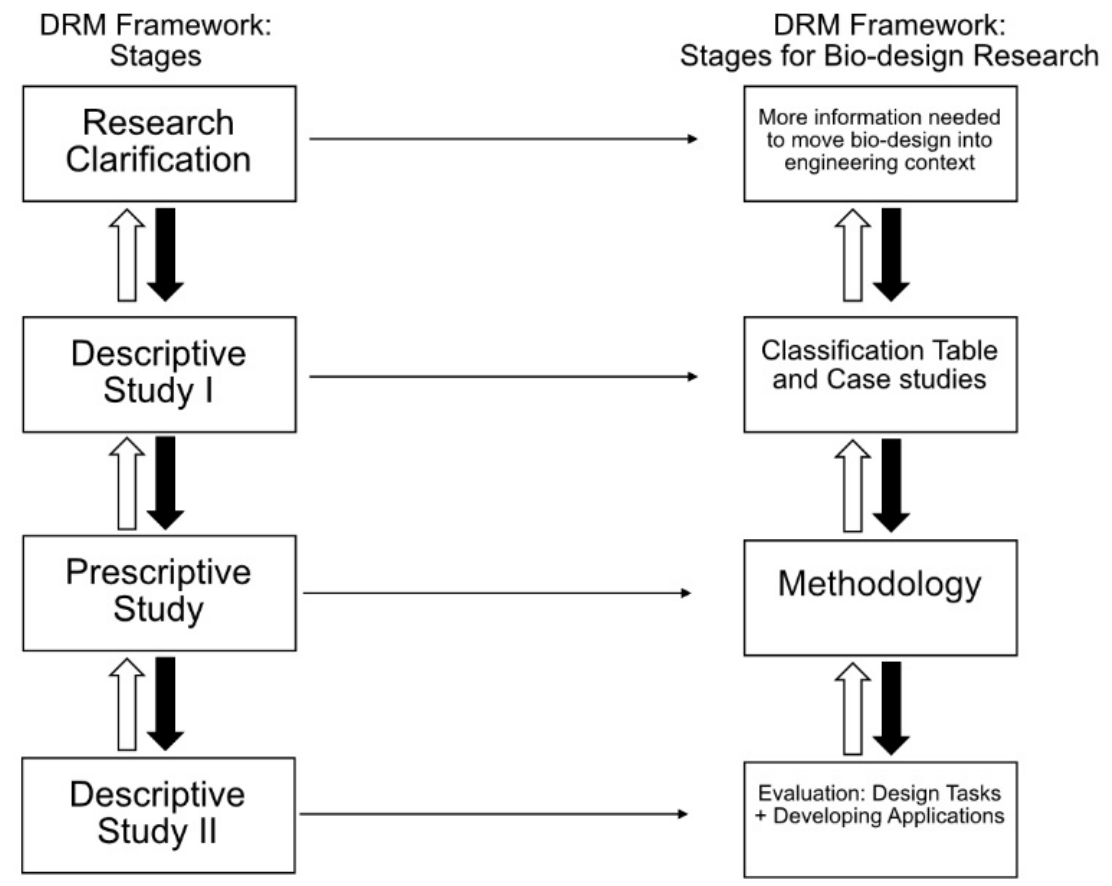

Figure 1. Design research methodology and modified design research methodology framework for the bio-design PhD 
The Design Research Methodology (DRM) framework below shows the progress of this research and the aim of this paper. The flow diagram on the left in Figure 1 shows the DRM framework as proposed by Blessing and Chakrabarti (2009). The flow diagram on the right shows this framework modified around the research found in this paper. The research clarification is the establishment that bio-design needs to be made more accessible for engineers. Currently, as detailed in this paper there is interest in the fields of art and design in collaboration with biologists as illustrated by the Bio Design Challenge (2017). The methodology presents an opportunity to move bio-design into an engineering context, without the need for highly specialised biological knowledge. As can be seen from Figure 1, the classification table presented in this paper and case studies that will be conducted present a research step towards the design methodology. The field of bio-design is emerging and thus insight through articles and publicly available information is somewhat limited. Interviews with companies and researchers working with bio-design applications are planned in order to gain a deeper insight what can inform the final methodology.

\section{Method}

This section presents the method of data collection which included characterisation of applications and their classification. The data was characterised by grouping applications according to several criteria: Technology Readiness Level (TRL), application sector, and bio-design class. This section also shows the means by which the final classification system was devised.

\subsection{Data collection}

In order to characterise current bio-design applications, information was extracted from sources which included journal articles, popular science magazine and company websites. The information was compiled in a classification table. Data collection was carried-out by document analysis and significant information was extracted from sources and placed accordingly in its corresponding column in the classification table. The classification table allowed for the systematic and side-by-side comparison of bio-design applications according to various criteria, such as organisms involved, non-living components and their interactions. Applications included those developed by companies as well as university-level research. A total of 25 company/university-level applications were reviewed and characterised.

The full classification table was used to compile existing bio-design applications. Table 1 presents the column headings extracted from the classification table. Application sector and Technology Readiness Level (TRL) will be discussed in Sections 3.2 and 3.3 respectively. Bio-design class and sub-class were identified as a result of the characterisation process. The two columns regarding the Presence of GMO and Reason for GMO shows if the application involves synthetic biology and the reasons for the genetic modification. Genetic modification concerns the presence of an organism with DNA that has been modified by human intervention. These organisms are said to be synthetic. Type of organism and Organism columns details the living or once living organism, and the Non-Living Component column presents the other non-organic elements of the application. The information presented in the Interaction column outlines the way in which living and non-living components collaborate to result in the application. Reason + Strength of collaboration presents the support for the interaction and its advantages over traditional manufacturing processes.

The classification table identified that the majority of applications are within the materials application sector, seven out of a total of 25 applications. Three of the seven applications: bioMASON (2016), BacillaFilla (Newcastle Team, 2010) and Bioconcrete (Jonkers et al., 2010) concern making or repairing building materials. Other material applications are: Ecovative, a company that produces material from mycelium for packaging (Ecovative, 2017), Bolt Threads a company that produces clothing from proteins similar to spiders' silk through a fermentation process (Bolt Threads, 2017), Biocouture, a project to produce 'vegetable leather' from cellulose and Bacs, a project to produce self-constructing packaging from bacterial cellulose (Fairs, 2014). All of four applications described use dead or inactivated microorganisms, two of which-Biocouture and Bacs- rely upon cellulose and two of which use a fermentation process- Ecovative and Biocouture. 
The classification table also enabled the identification that the two applications in the remediation category: bacteria to clean nuclear waste and bacteria to clear oil spills. Both applications involve bacteria that are not genetically modified and are both university-level projects. Bacteria that clear oil spills are indigenous bacteria that were found to have this capability (Blackwell Publishing Ltd, 2005) and in the case of cleaning nuclear waste, the interaction with the non-living components enabled bacteria to detect uranium and harvest it (Society for General Microbiology, 2009).

Table 1. Column headings extracted from the classification table

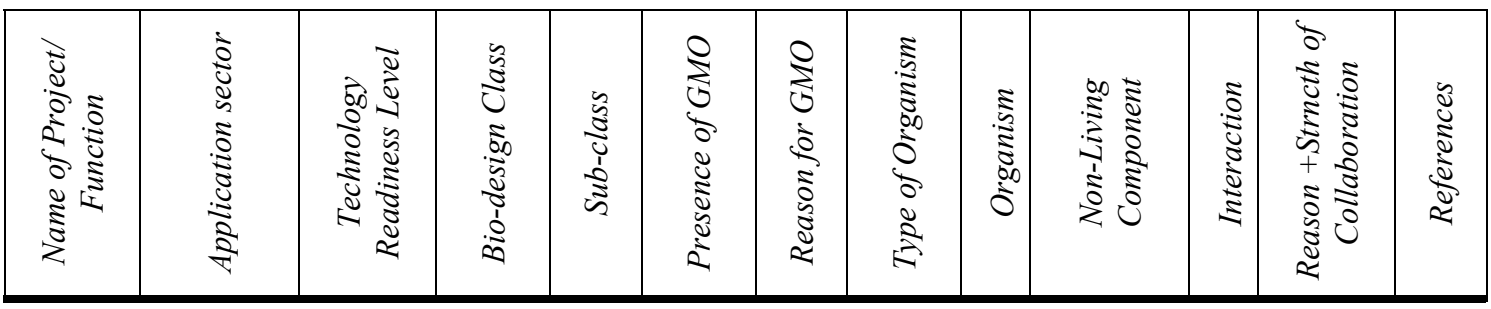

The information on bio-design applications was found from a range of sources including scientific journals, magazine articles and video clips. Due to the novelty of the field, bio-design applications were hard to locate in literature, similarly to bio-inspired design applications. The emerging term bio-design was used infrequently. Applications were identified by searching for novel materials such as those made from mycelium and bacterial cellulose, novel architectural processes, and the integration of bacteria, specifically synthetic bacteria into ecological objects.

Characterisations of existing applications will inform the criteria, parameters and format of the design methodology. Applications were characterised by placing into groups according to application sector and technology readiness level. The results of this process lead to the conception of bio-design classes; as shown in the Section 4.0 Findings.

\subsection{Characterisation: Application sector}

In order to classify applications, two schemes were reviewed, presented in 1) William Myer's book Bio Design: nature science creativity (Myers, 2012) and 2) the Bio Design Challenge (2017).

In the book Bio Design: nature science creativity, Myers (2012) categorises bio-design applications in the following: "The Architectural Hybrid: Integration of bio-design principals in architecture, Ecological Engineering: Objects and processes in which new ecologies have replaced traditional industrial and mechanical systems, Experimental Functions: Speculative design, design fiction and provocations, Dynamic Beauty: Completed pieces of art that incorporate bio-design principals" (Myers, 2012).

Bio Design Challenge (BDC) is an international competition for art and design university students to develop bio-design applications (Bio Design Challenge, 2017). Design students work in conjunction with biologists and synthetic biologists to develop bio-design applications. BDC defines applications in the following categories: Architecture, Communication, Energy, Food, Materials, Medicine, Transport and Water.

The categories defined by Myer, 2012 were formulated around pre-existing bio-design applications. However, those put forward by Bio Design Challenge sought to highlight potential application sectors in which students may choose to investigate possible bio-design solutions.

Bio-design requires deep biology knowledge, thus categorisation of applications in sectors may allow for easier access to this novel design principle by engineers. As a result of the review of current applications, the following application sectors were proposed: Material, Fuel, Architecture, Biosensor, Remediation, Robotic, Ecological Object, and Light. The sectors therefore present the areas in which there are current applications as opposed to potential ones. Current applications, grouped according to application sector is shown in Figure 4.

These categories were chosen because those outlined in Myers, 2012 were too broad for thorough investigation of the design process. The categories defined were not application-orientated but focused on three discrete categories which may be further divided according to applications' specific functions. 
In addition, the Bio Design Challenge categories were developed to highlight potential application sectors and thus many were not relevant.

Information was extracted from sources and placed in classification table, after which application sectors were allocated. The category "Ecological Object" was included for those applications without a clear category.

\subsection{Characterisation: Technology readiness level}

Technology readiness level (TRL) numbers were assigned to each bio-design applications included in the classification table. TRL is a type of measurement system created by NASA to assess the level of maturity of a particular technology (NASA, 2012). Figure 2 below was taken from the NASA website, although many variations of this diagram have been produced.

The spectrum ranges from TRL 1 to TRL 9; TRL 9 is the most mature technology.

A technology is evaluated against the parameters for each level and then assigned a particular level based on the progress of the project. In order for a TRL rating to be assigned to a project, it must have achieved the description, as shown in Figure 2 (NASA, 2012).

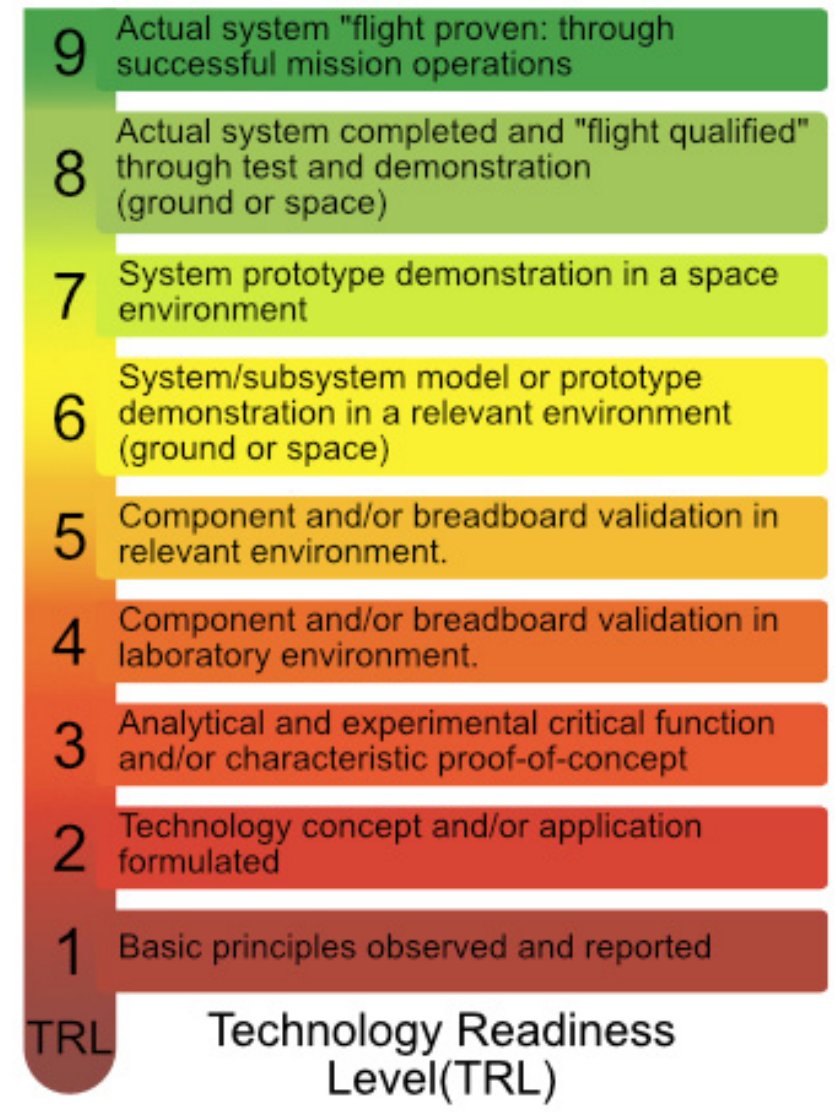

Figure 2. Technology readiness level spectrum. Adapted from figure found in NASA (2012)

Figure 3 shows an interpretation of the TRL spectrum produced for the sake of this project, according to its particular requirements. The TRL groups as shown in Figure 3 were ascertained by grouping and conflating two of the classic TRL levels. For the purpose of this project it was not necessary to pinpoint the exact TRL. Furthermore, many of the companies/research groups are developing highly novel technologies and thus information is hard to locate. As shown in Figure 3, in order to easily allocate numbers to applications, questions were assigned to each TRL number group e.g. TRL 8-9: Is this technology a commercially available product? A TRL band was assigned to each application and a matrix was constructed, as shown in Figure 3. 

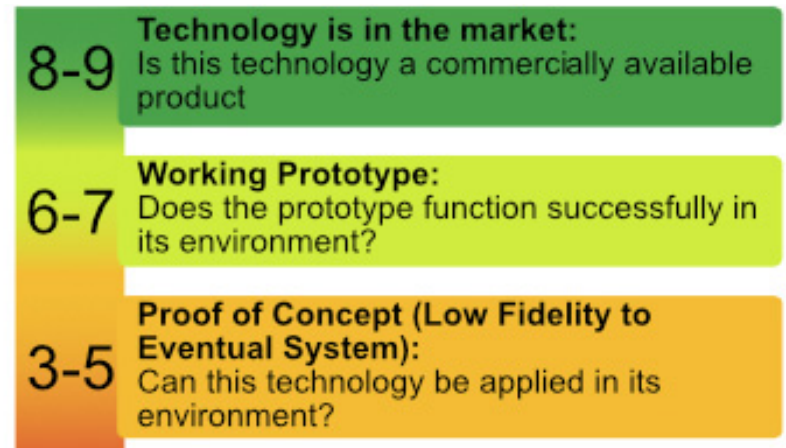

Speculative Design/Concept:
1-2 Has an initial framework been put down for
how this may be achieved?

Technology Readiness
Level(TRL)

Figure 3. Technology readiness level spectrum adapted for the purpose of this research

Figure 4, below shows current applications of bio-design grouped according to both TRL number and category of application. The yellow spots signify projects at university-level research. As can be seen in the graph, the majority of bio-design applications characterised were in the Material category. Furthermore, it can be observed that all of the applications in Architecture were at TRL 1-2. The least number of applications were in Robotic, Ecological Object, Light and Remediation sectors. Remediation and Robotic applications have not proceeded past TRL 3-4. Fuel, Material, Ecological Object and Light sectors all have applications at TRL 8-9.

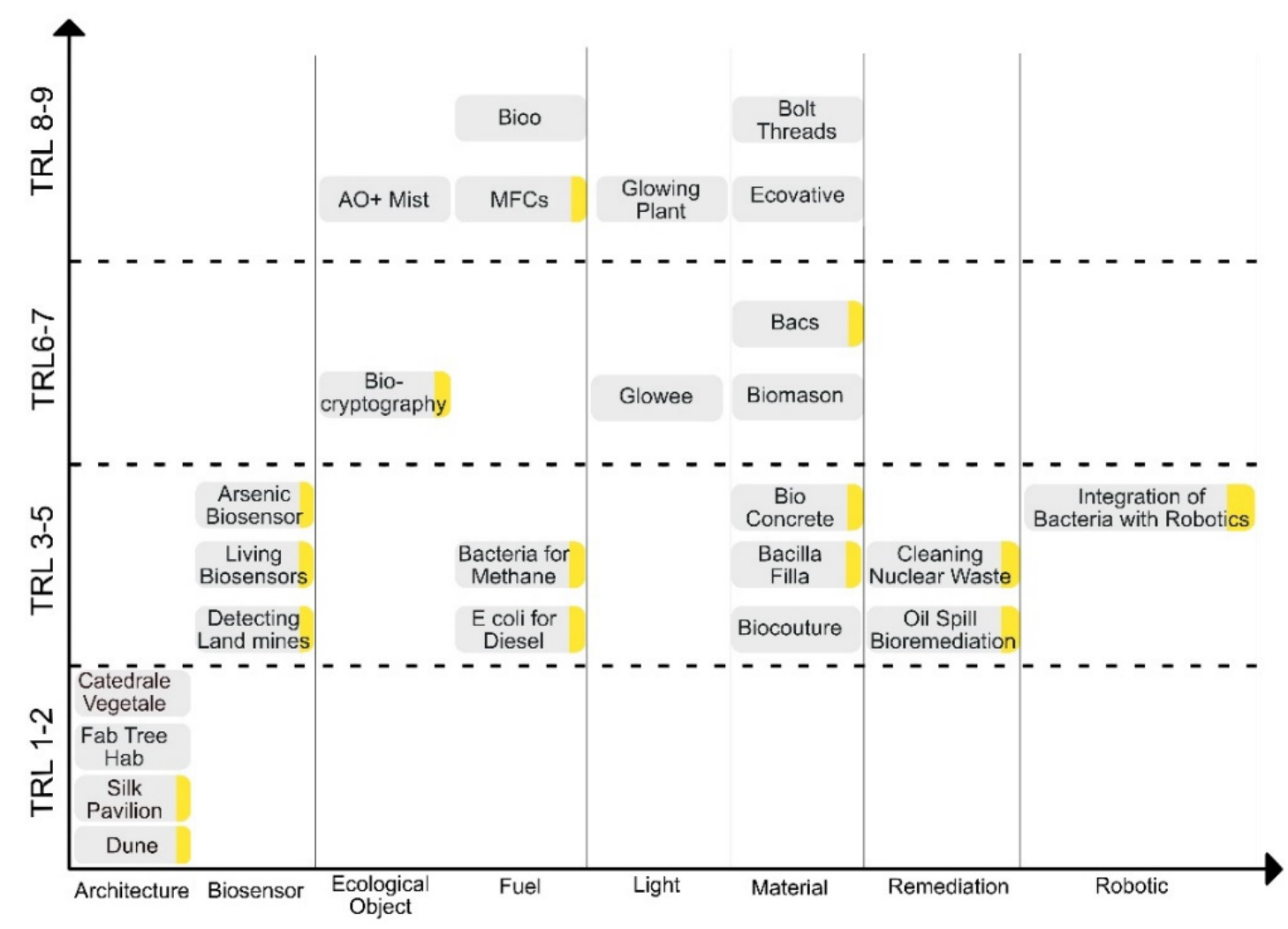

Figure 4. Bio-design applications plotted on a graph of categories against TRL groups 
Future work will concern the further investigation of reasons behind the trends observed in this graph. The mapping of the identified bio-design examples to TRL revealed that the majority of these are at relatively low TRL and that the examples were found in a limited number of application sectors. Thus, any bio-design methodology would need to consider how these examples can be moved to a high level of TRL and to facilitate the conception of bio-design solutions in further application sectors.

\section{Findings}

This section presents and discusses the major findings resulting from the characterisation of the biodesign applications. Also presented are the bio-design classes that were developed as a result of the characterisation. Part of the characterisation process identified the need to develop a new bio-design classes, i.e. a new classification scheme, these are presented below, and can be seen as the foundation for bio-design methodologies.

From the review of existing applications, it has established that there is an interest in bio-design in a wide range of fields. Individuals from a variety of research fields have begun to recognise the largely unrealised potential that bacteria and other organisms pose. Applications for biological processes are found by re-framing living processes into a human context, although it has been difficult to ascertain the criteria that contribute to creating successful applications. This is due to the lack of bio-design in literature and furthermore, the confidentiality that exists around the highly novel cutting-edge bio-design applications. It was observed that the more mature the technology, the more confidential the companies. From the characterisation of applications through grouping into TRL and application sectors, it was ascertained that there are two major classes of bio-design applications: "Living Organism" and "Dead Biomass". This is expanded upon in the following Section 4.1 Classes of Bio-Design Applications.

\subsection{Classes of bio-design applications}

Characterisation of bio-design applications has defined two major classes of bio-design, included as a column heading in the classification table. The two categories that exist involve a. Living organisms and b. Dead biomass. As is illustrated in Figure 5, both classes can be sub-divided and further categorised in terms of further details about the application and the presence of a genetically modified organism (GMO). At least one application has been characterised that for all the sub-classes illustrated in Figure 1 , other than the "Consortia" sub-class; the red cross denotes this.

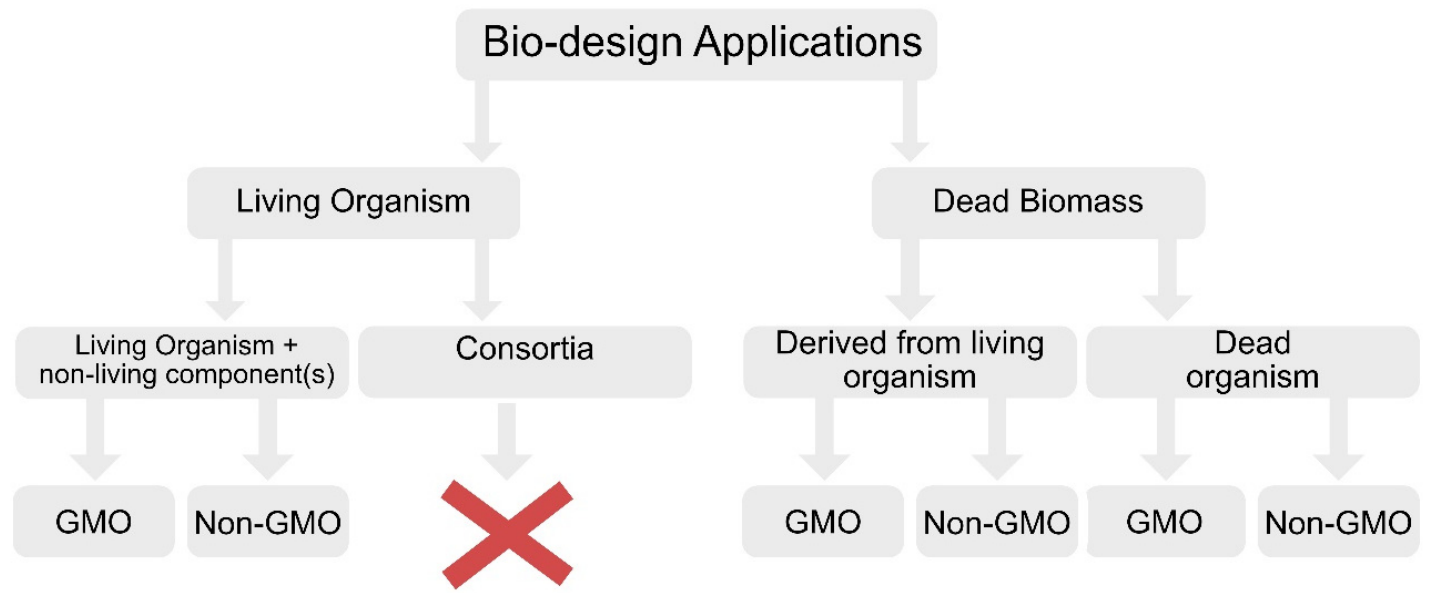

Figure 5. Classes and sub-classes of bio-design applications

a) Living organism(s): Applications that involve a living organism. It was found that the vast majority of bio-design applications fit into this category, including most notably, the incorporation of bacteria in concrete (Belie, 2016). These are mapped in Table 2. Furthermore, the literature review revealed that organisms involved in these interactions are mostly bacterial species (Blackwell Publishing Ltd, 2005; Rice, 2008; Glowee, 2016). As can be seen from Figure 5 , this category may be sub-dived further in terms of those interactions in which genetically 
modified organisms (GMO) organisms are involved. Some of the collaborations involve synthetic organisms, although not all. Examples of the Living Organism category can be seen in Table 2. The applications differ in terms of the other components involved. Some of the applications require minimal interaction with non-living components, for example E.coli for data storage. In this case, only the information to be stored is needed. Other applications have many more requirements for a successful interaction to take place such as Microbial Fuel Cells which require an anode, cathode, proton exchange membrane and carbon source such as glucose (Rahimnejad et al., 2015).The Living Organism category also includes interactions between populations of two different organisms, called consortia. A paper written by Hays et al. (2015) has been instrumental for the researching of biological consortia. This paper discusses the possibility of engineering microbial consortia and as such sets out environmental parameters to be taken into consideration in order to optimise microbial communities. These include: microfluidics, spatial patterning including moulding, 3D printing, inkjet printing and fibre structure as well as communication controls (Hays et al., 2015). Furthermore, the paper reviews the advantages of consortia such as robustness and division of labour. Robustness is an emergent property of microbial communities and is manifested by their avoidance of perturbation and division of labour is an advantage because the system has an expanded access to functional and metabolic capabilities (Hays et al., 2015). However, there are no example applications. No engineered applications involving biological consortia have been identified, although an example of a biological consortium that occurs organically in nature has been recently identified within the area of agriculture: Ectomycorrhizal fungi associate with plants, allowing the plants to overcome nitrogen limitation and thus take full advantage of the $\mathrm{CO}_{2}$ fertilization effect. This will allow plants associated with ectomycorrhizal fungi to further slow-down climate change (Terrer et al., 2016). This finding concerns an interaction that was already occurring in nature; it was not engineered. The Hays et al. (2015) paper as well as these recent findings highlight the potential of biological consortia and how they may be taken advantage of in the future if they can be engineered and/or appropriated for human purposes.

Table 2. Examples of bio-design applications from the "Living Organism" class

\begin{tabular}{|c|c|c|c|}
\hline Bio-design Application & Living Organism & Presence of $G M O$ & Reference \\
\hline $\begin{array}{l}\text { Bacteria to produce } \\
\text { diesel fuel- } \\
\text { Bacteria produce carbon- } \\
\text { neutral biofuel diesel }\end{array}$ & Escherichia coli & YES & Howard et al., 2013 \\
\hline $\begin{array}{l}\text { Cheaper cellulosic } \\
\text { ethanol- } \\
\text { Production of ethanol } \\
\text { using bacteria }\end{array}$ & $\begin{array}{l}\text { Geobacillus family } \\
\text { (Organism TM242) }\end{array}$ & YES & $\begin{array}{l}\text { Society for General } \\
\text { Microbiology, } 2008\end{array}$ \\
\hline $\begin{array}{l}\text { Microbial fuel cell- } \\
\text { Bacterial species to } \\
\text { generate electricity }\end{array}$ & $\begin{array}{l}\text { Various bacterial } \\
\text { species inc. } \\
\text { Saccharomyces } \\
\text { cerevisiae }\end{array}$ & $\mathrm{NO}$ & Rahimnejad et al., 2015 \\
\hline $\begin{array}{l}\text { Fibre-based digital } \\
\text { fabrication- } \\
\text { Silk worms to produce } \\
\text { archietcural model } \\
\end{array}$ & Bombyx mori & NO & Oxman et al., 2014 \\
\hline $\begin{array}{l}\text { Detecting landmines- } \\
\text { Bacteria to detect } \\
\text { presence of landmines }\end{array}$ & Escherichia coli & YES & Aguilar, 2009 \\
\hline
\end{tabular}

b) Dead Biomass: Applications involving non-living biomass. In this case, the class can be subdivided into applications in which the dead biomass was derived from a living organism and applications in which the dead biomass was once a living organism itself. These two categories 
can be further sub-divided into those that are genetically modified organisms (GMO) and those that are not genetically modified. Table 3 below shows all 'Dead Biomass' applications currently identified as well as the sub-type of collaboration.

Table 3. Examples of bio-design applications from the "Dead Biomass" class

\begin{tabular}{|l|l|l|l|l|}
\hline $\begin{array}{l}\text { Bio-design } \\
\text { Application }\end{array}$ & $\begin{array}{l}\text { Dead } \\
\text { Biomass }\end{array}$ & $\begin{array}{l}\text { Sub-type of } \\
\text { collaboration }\end{array}$ & $\begin{array}{l}\text { Presence of } \\
\text { GMO }\end{array}$ & Reference \\
\hline Biocouture & Cellulose & $\begin{array}{l}\text { Derived from once } \\
\text { living organism }\end{array}$ & NO & Fairs, 2014 \\
\hline Ecovative & Mycelium & Dead organism & NO & Ecovative, 2017 \\
\hline Bolt Threads & Protein & $\begin{array}{l}\text { Derived from once } \\
\text { living organism }\end{array}$ & YES & Bolt Threads, 2017 \\
\hline
\end{tabular}

\section{Discussion and conclusions}

The aim of the research was to review current bio-design applications and to develop bio-design classes in the form of a scheme. The classification system of current bio-design applications presents the first step towards the creation of a design methodology. The existing bio-design applications were reviewed and information was extracted and placed in the classification table. Assignment of TRL numbers and categories of application allowed data analysis and full characterisation of applications. As a result of this process, discrete classes were identified, into which all the applications were placed.

The conception of this classification system is a major first step towards the final design methodology- the long-term goal of this research. It also presents a contribution to researchers and designers alike who are working in this new emerging field. Furthermore, the classification system will inform the key details of the design methodology such as the criteria and parameters included as well as format. The identification of a classification system also illustrates that it is possible to create a formulism around bio-design.

This research has collected bio-design applications into a database, and provided a full review of the biodesign applications. This, together with characterisation of the applications has never been achieved before. From the classification table, it is can be observed that the majority of bio-design applications are within the category of "living organism + non-living component" and are "non-GMO" sub-classes. The majority of applications included bacterial organism, followed by other microorganisms such as yeast and fungi and lastly insects. All the applications characterised used microorganism species apart from the digital fabrication application developed by Oxman et al. (2014) in which silk worms were used. The incorporation of microorganisms present a clear advantage in terms of their ability to react spontaneously to novel stimuli in real-time in addition to their capabilities in terms of integrating vast data from their environment and coordinating an appropriate response. These qualities are particularly significant in the integration of plasmodium with robotics. Cells are able to recognise damage and respond by self-repairing and process information highly efficiently compared to computational tools (Gough et al., 2009).

This research presents key contributions to current knowledge. Bio-design applications have been compiled and reviewed in a way that has never been conducted before. The review has shown that there is a huge amount of research that incorporates bio-design principles, across a range of fields and technology maturities. However the unified field of bio-design is novel and under-investigated. This conclusion can also point to the importance of a design methodology. This statement is amplified by the finding that so far, no methodology for bio-design exists. The current applications are not as a result of a methodology but occur in an unsystematic and unscientific ad hoc process. This is typical of emerging fields. The current state of applications have limited engineering functionality, thus a methodology and overview of existing bio-design applications including their sectors supports the objective of moving bio-design to an engineering context.

\section{References}

Aguilar, E. (2009), Bacteria make light work of detecting landmines. [online] SciDev.Net. Available at: https://www.scidev.net/global/health/news/bacteria-make-light-work-of-detecting-landmines.html (accessed 02.12.2017). 
Ahmed-Kristensen, S., Christensen, B.T. and Lenau, T. (2014), "Naturally original: Stimulating creative design through biological analogies and random images", Proceedings of the 13th International Design Conference (DESIGN 2014), Dubrovnik, Croatia, May 19-22, 2014, The Design Society, Glasgow, pp. 427-436.

Armstrong, R. (2016), "Embodied intelligence: changing expectations in building performance", Intelligent Buildings International, Vol. 8 No. 1, pp. 4-23. https://doi.org/10.1080/17508975.2015.1050581

AskNature (2016), AskNature. [online] Biomimicry Institute. Available at: https://asknature.org (accessed 08.12.2017).

Belie, N.D. (2016), "Application of bacteria in concrete: a critical review", RILEM Technical Letters, Vol. 1, pp. 56-61. https://doi.org/10.21809/rilemtechlett.2016.14

Bio Design Challenge (2017), What is the Bio Design Challenge? [online] Bio Design Challenge. Available at: http://biodesignchallenge.org/about (accessed 13.12.2017).

bioMASON (2016), Technology. [online] bioMason. Available at: http://biomason.com/technology (accessed 14.12.2017).

Blackwell Publishing Ltd (2005), A Hope For Oil Spill Bioremediation. [online] ScienceDaily. Available at: https://www.sciencedaily.com/releases/2005/05/050517063708.htm (accessed 06.12.2017).

Blessing, L.T.M and Chakrabarti, A. (2009), DRM, a Design Research Methodology, Springer-Verlag, London, UK. https://doi.org/10.1007/978-1-84882-587-1

Bolt Threads (2017), Technology. [online] Bolt Threads. Available at: https://boltthreads.com/technology (accessed 29.06.2017).

Ecovative (2017), Mycelium. [online] Ecovative. Available at: http://www.ecovativedesign.com/how-it-works (accessed 11.12.2017).

Fairs, M. (2014), Microbes are the factories of the future. [online] Dezeen. Available at: https://www.dezeen.com/2014/02/12/movie-biocouture-microbes-clothing-wearable-futures (accessed 11.12.2017).

Fernandez-Marquez, J.L., Di Marzo Serugendo, G., Montagna, S., Viroli, M. and Arcos, J.L. (2013), "Description and composition of bio-inspired design patterns: A complete overview", Natural Computing, Vol. 12 No. 1, pp. 43-67. https://doi.org/10.1007/s11047-012-9324-y

Glowee (2016), Technology. [online] Glowee. Available at: http://www.glowee.eu (accessed 06.12.2017).

Glowing Plant (2013), Project Background. [online] Glowing Plant. Available at: http://www.glowingplant.com (accessed 14.12.2017).

Goel, A. (2011), Augmented Intelligence Platform. [online] Design and Intelligence Lab. Available at: http://dilab.cc.gatech.edu/dane (accessed 15.02.2017).

Gough, J., Jones, G., Lovell, C., Macey, P., Morgan, H. et al. (2009), "Integration of cellular biological structures into robotic systems", Acta Futura, Vol. 3, pp. 43-49. https://doi.org/10.2420/AF03.2008.36

Hays, S.G., Patrick, W.G., Ziesack, M., Oxman, N. and Silver, P.A. (2015), "Better together: Engineering and application of microbial symbioses", Current Opinion in Biotechnology, Vol. 36, pp. 40-49. https://doi.org/10.1016/j.copbio.2015.08.008

Helms, M.E., Vattam, S.S., Goel, A.K. and Weissburg, M.J. (2008), "Problem-Driven and Solution-Based Design: Twin Processes of Biologically Inspired Design", Proceedings of the 28th Annual Conference of the Association for Computer Aided Design in Architecture (ACADIA), Minneapolis, MN, October 16-19, 2008, pp. 94-101.

Howard, T.P., Middelhaufe, S., Moore, K., Edner, C., Kolak, D.M. et al. (2013), "Synthesis of customized petroleum-replica fuel molecules by targeted modification of free fatty acid pools in Escherichia coli", Proceedings of the National Academy of Sciences of the United States of America, Vol. 110 No. 19, pp. 76367641. https://doi.org/10.1073/pnas.1215966110

ISO/TC266 (2015), Biomimetics - Terminology, concepts and methodology. [online] ISO. Available at: https://www.iso.org/obp/ui/\#iso:std:iso:18458:ed-1:v1:en (accessed: 04.03.2018).

Jonkers, H.M., Thijssen, A., Muyzer, G., Copuroglu, O. and Schlangen, E. (2010), “Application of bacteria as selfhealing agent for the development of sustainable concrete", Ecological Engineering, Vol. 36 No. 2, pp. 230235. https://doi.org/10.1016/j.ecoleng.2008.12.036

Keshwani, S, Lenau, T., Ahmed-Kristensen, S. and Chakrabarti, A. (2013), "Benchmarking bio-inspired designs with brainstorming in terms of novelty of design outcomes", Proceedings of the 19th International Conference on Engineering Design (ICED 2013), Seoul, Korea, August 19-22, 2013, pp. 21-30.

Keshwani, S., Lenau, T.A., Ahmed-Kristensen, S. and Chakrabarti, A. (2017), "Comparing novelty of designs from biological-inspiration with those from brainstorming”, Journal of Engineering Design, Vol. 28 No. 1012, pp. 654-680. https://doi.org/10.1080/09544828.2017.1393504

Kyoo-Chul, P., Chhatre, S. and Srinivasan, S. (2013), "Optimal Design of Permeable Fiber Network Structures for Fog Harvesting”, Langmuir, Vol. 29 No. 43, pp. 13269-13277. https://doi.org/10.1021/la402409f 
Mak, T.W. and Shu, L.H. (2008), “Using descriptions of biological phenomena for idea generation”, Research in Engineering Design, Vol. 19 No. 1, pp. 21-28. https://doi.org/10.1007/s00163-007-0041-y

Myers, W. (2012), Bio design Nature Science Creativity, Thames \& Hudson, London, UK.

NASA (2012), Technology Readiness Level. [online] NASA. Available at: https://www.nasa.gov/directorates/heo/scan/engineering/technology/txt_accordion1.html (accessed 08.12.2017).

Newcastle Team (2010), BacillaFilla: Fixing Cracks in Concrete. [online] iGEM. Available at: https://2010.igem.org/Team:Newcastle (accessed 13.12.2017).

Oxman, N., Laucks, J., Kayser, M., Duro-Royo, J. and Gonzales-Uribe, C. (2014), "Silk Pavillion: Case Study in Fibre-Based Digital Fabrication", FABRICATE Conference Proceedings, ETH Zurich, Switzerland, February 14-15, 2014, pp. 248-255.

Rahimnejad, M., Adhami, A., Darvari, S., Zirepour, A. and Oh, S.E. (2015), "Microbial fuel cell as new technology for bioelectricity generation: A review", Alexandria Engineering Journal, Vol. 54 No. 3, pp. 745-756. https://doi.org/10.1016/j.aej.2015.03.031

Rice, J. (2008), Detecting Pollution with Living Biosensors. [online] MIT Technology Review. Available at: https://www.technologyreview.com/s/410834/detecting-pollution-with-living-biosensors/ (accessed 06.03.2017).

Shang, L., Gu, Z. and Zhao, Y. (2016), "Structural color materials in evolution", Materials Today, Vol. 19 No. 8 , pp. 420-421. https://doi.org/10.1016/j.mattod.2016.03.004

Society for General Microbiology (2008), Compost heap bacteria could provide 10\% of UK transport fuel needs. [online] ScienceDaily. Available at: https://www.sciencedaily.com/releases/2008/09/080908203021.htm (accessed 15.12.2017).

Society for General Microbiology (2009), Using Waste To Recover Waste Uranium. [online] ScienceDaily. Available at: https://www.sciencedaily.com/releases/2009/09/090907013804.htm (accessed: 19.03.2018).

Terrer, A.C., Vicca, S., Hungate, B.A., Phillips, R.P. and Prentice, C. (2016), "Mycorrhizal Association as a Primary Control of the CO2 Fertilization Effect", Science, Vol. 353 No. 6294, pp. 72-74. https://doi.org/10.1126/science.aaf4610

Wen, L., Weaver, J.C. and Lauder, G.V. (2014), "Biomimetic shark skin : design, fabrication and hydrodynamic function”, Journal of Experimental Biology, Vol. 217 No. 10, pp. 1656-1666. https://doi.org/10.1242/jeb.097097

Roya Esat, PhD Candidate

Imperial College London, Dyson School of Design Engineering

55 Bramley Road, N14 4HA London, United Kingdom

Email: r.esat16@imperial.ac.uk 